This item was submitted to Loughborough's Research Repository by the author.

Items in Figshare are protected by copyright, with all rights reserved, unless otherwise indicated.

\title{
Peroxide crosslinking of rigid poly(vinyl chloride)
}

PLEASE CITE THE PUBLISHED VERSION

https://doi.org/10.1002/vnl.20158

PUBLISHER

(c) John Wiley \& Sons

VERSION

AM (Accepted Manuscript)

LICENCE

CC BY-NC-ND 4.0

REPOSITORY RECORD

Gunewardena, J. Anoma G.S.G., and Marianne Gilbert. 2009. "Peroxide Crosslinking of Rigid Poly(vinyl Chloride)". figshare. https://hdl.handle.net/2134/5006. 
This item was submitted to Loughborough's Institutional Repository (https://dspace.lboro.ac.uk/) by the author and is made available under the following Creative Commons Licence conditions.

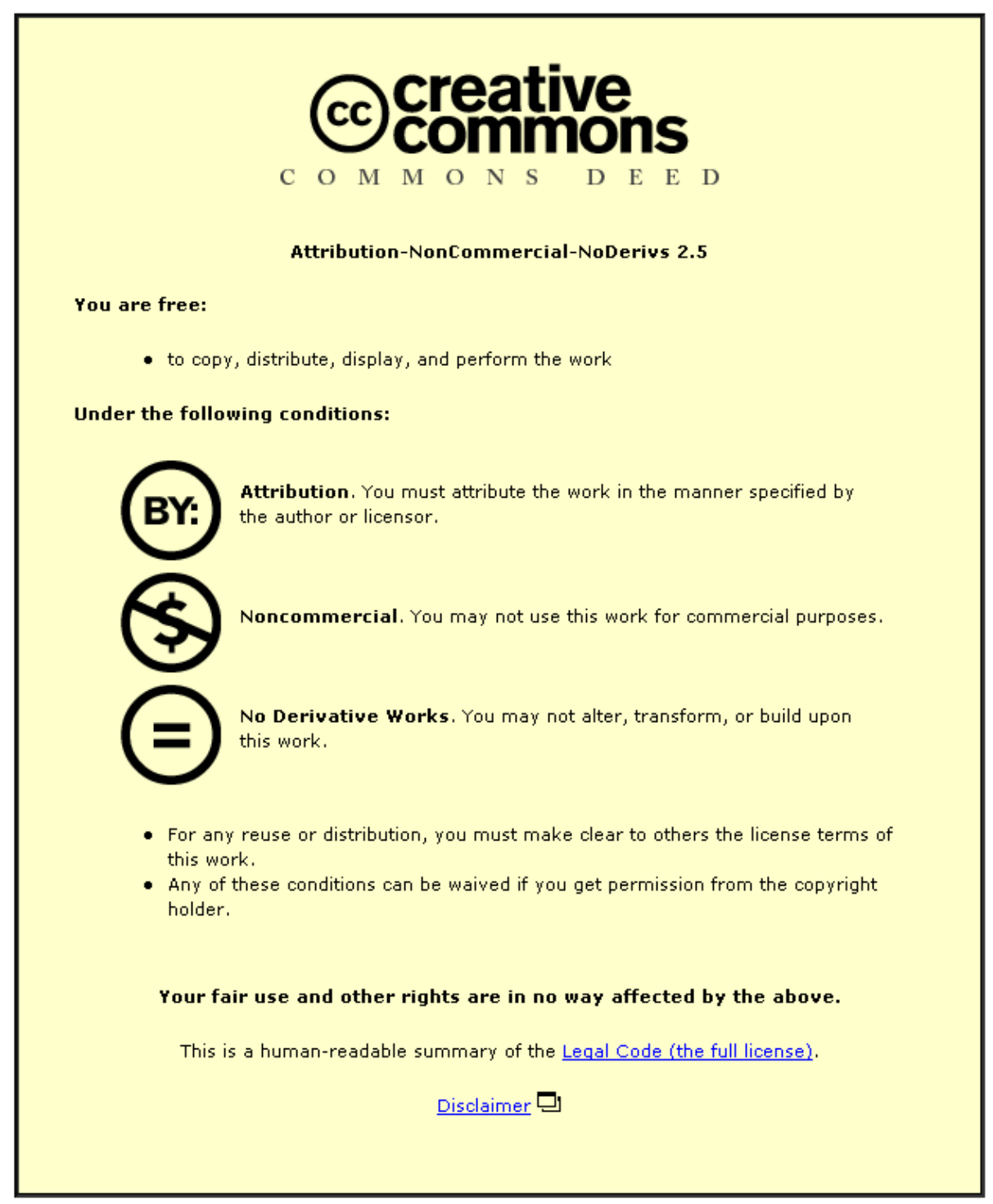

For the full text of this licence, please go to: http://creativecommons.org/licenses/by-nc-nd/2.5/ 
Peroxide Crosslinking of Rigid Poly(vinyl chloride)

\section{Anoma Gunewardena and Marianne Gilbert}

Institute of Polymer Technology and Materials Engineering

Loughborough University

Loughborough, Leicestershire

LE11 3TU 


\title{
Peroxide Crosslinking of Rigid Poly(vinyl chloride) \\ Anoma Gunewardena and Marianne Gilbert \\ Institute of Polymer Technology and Materials Engineering \\ Loughborough University \\ Loughborough, Leicestershire
}

LE11 3TU

\begin{abstract}
Peroxide crosslinking of unplasticised poly(vinyl chloride), PVC with trimethylolpropane trimethacrylate (TMPTMA) has been investigated. Formulations used in this work contained a nontoxic lead free stabiliser and showed good colour and heat stability. The samples have been examined by differential scanning calorimeter(DSC) and tensile properties at room temperature and at $130^{\circ} \mathrm{C}$ were measured. Gel content or tetrahydrofuran (THF) insoluble material was measured as an indication of crosslinking. It is shown that premature crosslinking can be avoided during processing. It was found that $190^{\circ} \mathrm{C}$ was the optimum processing temperature for maximum gel content. The residual unsaturation was monitored using FTIR..
\end{abstract}

Key words : PVC, Trimethylolpropane trimethacrylate (TMPTMA), Gel content, Peroxide crosslinking 


\section{Introduction:}

Crosslinking has been shown to improve the elevated temperature properties of rigid PVC. Irradiation crosslinking of PVC has been studied comprehensively and used in commercial applications, such as wire and cable insulations. However, irradiation by itself does not form any appreciable amount of crosslinking, instead the material formed is less stable than the original PVC.[1,2,3] Hence, a polyfunctional monomer was introduced as the crosslinking agent, and low doses of radiation were used for crosslinking, minimising the degradation of PVC.

Initiated by irradiation, polyfunctional monomer activates and produces homopolymerisation of monomer, graft copolymerisation of the monomer onto PVC and graft crosslinking between polymer chains. Various classes of polyfunctional unsaturated monomers have been investigated which included divinylbenzene[1], allyl esters[4], triacrylates[5], dimethacrylates[1,5] and trimethacrylates[5-10]. Out of these systems, polyfunctional acrylates and methacrylates especially trifunctional monomers such as trimethylolpropane trimethacrylate (TMPTMA) and trimethylolpropane triacrylate have shown to be the most effective due to their good compatibility with PVC.

In the presence of crosslinking monomer, irradiation produces homopolymerisation of the monomer, graft copolymerisation of the monomer onto PVC and graft crosslinking between PVC chains. In principle, any polyfunctional unsaturated monomer is capable of promoting crosslinking.

In the 1990s a number of different methods for the chemical crosslinking[11,12,13] of PVC has been studied: these include the use of silanes[12] and peroxides[13]. Results have shown that it is possible to obtain crosslinkable formulations with both systems. An ongoing research programme in our laboratories 
has been concerned with the crosslinking of PVC. Most work has been concerned with the crosslinking (irradiation, silane, peroxide) of flexible PVC. More recently it has been shown that the crosslinking can be produced in rigid PVC by the use of peroxides. It was found that $\mathrm{T}_{\mathrm{g}}$ can be increased by $35^{\circ} \mathrm{C}$ by crosslinking using Trigonox 29-40B-pd (1,1-di-t-butyl peroxy -3,3,5-trimethyl cyclohexane) supplied by Akzo Nobel.

In a subsequent project[14] conducted in collaboration with Crompton Corporation, rigid PVC was crosslinked by 1,1-di-(t-butylperoxy)-3,3,5-trimethyl cyclohexane peroxide (USP 495D) and ethyl -3,3-di-(t-butylperoxy) butyrate peroxide (USP 333M) in the presence of TMPTMA. The crosslinked PVC samples had gel contents (\% insoluble polymer) up to $50 \%$, depending on the peroxide and conditions used, and crosslinking improved tensile properties at elevated temperature for rigid PVC. The penetration resistance, $\mathrm{T}_{\mathrm{g}}$ and softening values of the crosslinked PVC samples were found to be higher than those of the uncrosslinked PVC samples. However, the $T_{g}$ of these crosslinked PVC samples showed a less significant increase than that with the Trigonox 29-40B-pd. Further, these samples were found to be brittle, which is likely to be related to the poor fusion of PVC during processing.

In the work reported here, a lead free heat stabiliser together with an alternative peroxide are used, and the aim of the present work is to investigate the optimum concentration of this new peroxide and TMPTMA required to improve the crosslinking and produce better physical and mechanical properties of the crosslinked material. The effect of the crosslinking additives on the fusion of PVC was also examined in an attempt to reduce the problem of brittleness observed earlier. 


\section{Experimental:}

\subsection{Materials}

The formulations investigated in the present work are given in Table 1, and the concentrations of TMPTMA and the peroxide Trigonox 29-C75 were varied according to the key given in Table 2. The PVC used was K60 PVC resin, EVIPOL SH6020 from EVC. The processing aid Paraloid K120N was supplied by Rohm and Haas, the waxes Loxiol G52 and eSlip 2053 by Henkel, and the Interwax GP25 by Hoescht. Crosslinking agent trimethylolpropane trimethacrylate (TMPTMA) was supplied by Rohm GmbH \& Co.KG and the peroxide Trigonox 29-C75(1,1-di(tertbutylperoxy)-3,3,5-trimethylcyclohexane) by Akzo Nobel. All materials were used without further purification.

\subsection{Sample Preparation}

\subsubsection{Dry Blending}

The samples were dry blended on a Henschel Internal Mixer. All the solid components were placed in the mixer at room temperature and mixed at 3000rpm until the temperature reached $80^{\circ} \mathrm{C}$ when the liquid additives (e.g. stabiliser and Loxiol G10V) were added. TMPTMA and the peroxide were added at $100^{\circ} \mathrm{C}$ and the blending was continued until the temperature reached $120^{\circ} \mathrm{C}$. Then the samples were dumped to the cooling chamber and cooled to room temperature $\left(27^{\circ} \mathrm{C}\right)$. This blending process takes approximately 20min to complete.

\subsubsection{Milling:}

The samples were milled on a two roll mill at $130^{\circ} \mathrm{C}$. A milled sheet of $3 \mathrm{~mm}$ thickness was produced using $200 \mathrm{~g}$ of the sample. It was rather difficult to form a 
band on the mill roll with these formulations, most probably due to the different lubricant used. It takes approximately 10 min complete the milling with comparison to the earlier formulation which takes only 7 min to produce the milled sheet. One way to overcome this problem is to increase the mill temperature. However, this would be likely to cause premature crosslinking.

\subsubsection{Compression Moulding:}

Milled sheets were pressed in a hydraulic press at 190 and $200^{\circ} \mathrm{C}$ under 20 tonne pressure for $5 \mathrm{~min}$.

\subsection{Testing and Characterisation}

\subsubsection{Gel Content}

The amount of insoluble PVC was determined by Soxhlet extraction for $24 \mathrm{~h}$ using tetrahydrofuran (THF) as the solvent. THF was removed by drying the thimbles for $16 \mathrm{~h}$ at $100^{\circ} \mathrm{C}$. In this work the term 'gel content' actually means the THF soluble material as the gel includes other insoluble materials which are in the formulation.

$$
\% \text { Gel content }=\left(\frac{W_{2}}{W_{1}}\right) \times 100
$$

$W_{1}=$ initial weight of sample

$W_{2}=$ weight of sample after the extraction in THF

\subsubsection{Colour Stability}

Colour changes of the pressed samples were given by Yellowness Index (YI) determined by the dr. Lange Colour Instrument. Increasing YI (measured by b ${ }^{*}$ ) corresponds to increasing colour of the sample. 


\subsubsection{Thermal Stability}

The thermal stability of the samples was determined in an oven fitted with a fan at $190^{\circ} \mathrm{C}$ according to ASTM 115-67. Small strips of samples were cut and placed on an aluminium foil holder, which was put on one of the oven trays. Strips were removed from the oven every 10min. and any change in colour observed.

\subsubsection{DSC}

Calorimetric measurements on the compression moulded sheets were carried out using a DSC 2010 thermal analyser fitted with a differential scanning calorimeter (DSC) cell, with heating rate of $20^{\circ} \mathrm{C} \mathrm{min}^{-1}$ under a nitrogen atmosphere. Gilbert et al.[15] showed that DSC traces can be used for the assessment of fusion of PVC. An endothermic baseline shift at $\mathrm{T}_{\mathrm{g}}$ and a broad endothermic melting range from 155 to $190^{\circ} \mathrm{C}$ were observed in a typical DSC trace obtained for PVC. The two endothermic peaks were identified and named as A and B, which changed with changing heat treatment or processing. The broad endotherm $\mathrm{A}$ is attributed to the wide range of secondary crystallites of varying order and/or size in PVC and its area provides an assessment of fusion. Further, it was shown that the B onset temperature is equal to the maximum processing temperature reached by the sample, which in turn is a valuable internal measure of processing temperature.

A typical DSC curve obtained for PVC is shown in figure 1. Glass transition temperature $\left(\mathrm{T}_{\mathrm{g}}\right)$ and the area of curve $\mathrm{A}$, with the area of additive peak $\mathrm{C}$ subtracted, were obtained using the DSC traces of the samples. Corrected heat of fusion was calculated as 
Corrected heat of fusion $=\left[\frac{\text { Heat of fusion for each sample }}{\% \text { PVC present in each sample }}\right] \times 100 \quad$ equation(2)

\subsubsection{Tensile Properties}

The ultimate tensile strength and the elongation at break were determined at room temperature and $130^{\circ} \mathrm{C}$ using a Hounsfield tester with a grip separation speed of 50mm/min. The samples were prepared according to ASTM D638-84. Eight test pieces were tested at each temperature. When tested at $130^{\circ} \mathrm{C}$, the samples were preconditioned for $20 \mathrm{~min}$. before testing.

\subsubsection{FTIR}

The infrared spectra of the samples were obtained using a Mattson 3000 FTIR spectrometer. The samples were prepared by compression of milled samples into thin films at 20 tons for $5 \mathrm{~min}$. at $170^{\circ} \mathrm{C}$ and $190^{\circ} \mathrm{C}$. Traces of pure TMPTMA monomer and a film of PVC alone (which was pressed using the same conditions) were obtained for comparison.

\section{Results and discussion}

\subsection{Gel content :}

Figure 2 shows the change in gel content with different amounts of TMPTMA and peroxide for the milled samples and the compression moulded sheets at two temperatures, 190 and $200^{\circ} \mathrm{C}$. Milled samples do not show high \% of gel, which indicates that premature crosslinking during processing can be largely avoided. Work done previously by several researchers[9,12,13] have shown that gel content 
increases with increasing TMPTMA. However, it was also observed that increasing peroxide concentration has less effect on gel content. Hence, as expected gel contents were increased with increasing TMPTMA, with the highest value of 55\% gel content obtained with 15phr of TMPTMA and 0.3phr of peroxide. Consistent with work[16] reported earlier it can be seen that increasing the amount of peroxide to $0.45 \mathrm{phr}$ does not increase the gel content. In fact it has decreased the gel content. It seems that excess peroxide probably causes chain scission associated with thermal degradation which causes the decrease in gel content hence decrease in crosslinking. Even though gel content has increased with pressing at both temperatures, increasing pressing temperature to $200^{\circ} \mathrm{C}$ slightly decreased the gel content. In earlier work by Thomas and Zheng[16] it was reported that an increase in gel content was observed when the pressing temperature was increased from 170 to $190^{\circ} \mathrm{C}$. However, increasing the pressing temperature to $200^{\circ} \mathrm{C}$ decreases the gel content. Although the peroxide will react more readily at $200^{\circ} \mathrm{C}$, the decrease in gel content suggests that side reactions may be occurring. Hence, considering these observations it can be assumed the $190^{\circ} \mathrm{C}$ could be the optimum temperature for crosslinking rigid PVC with peroxide.

\subsection{Colour stability :}

The colour stability of different samples were measured by yellowness index (measured by yellowing - $b^{*}$ ) as shown in figure 3. Even though the appearance of all the samples were similar to the naked eye, pressed sheets containing TMPTMA and peroxide showed very slight change in colour (when measured by $b^{*}$ ) compared with the sheet with no TMPTMA and peroxide. However, increase in pressing temperature to $200^{\circ} \mathrm{C}$ has also made the sheets very slightly yellowier than the sheets pressed at lower temperature of $190^{\circ} \mathrm{C}$. These observations show that some chemical 
degradation occurrs in PVC when TMPTMA and peroxide are present in the formulation which are also promoted by increasing temperature.

\subsection{Thermal Stability:}

Change in colour in pressed samples of formulations NF1 to NF5, when exposed to a temperature of $190^{\circ} \mathrm{C}$ is shown in figure 4 . It can be seen from this figure that all the formulations show adequate stability to heat degradation as none show significant discolouration until they have been in the oven for at least 50 min.(The normal requirement for adequate stability is 30 minutes at $190^{\circ} \mathrm{C}$ using this test). Hence, it can be assumed that Tinstab BTS71N (n-Butyltin tris(2 ethylhexylthio-glycolate) provides adequate heat resistance. However, it can be seen that samples which contain TMPTMA and peroxide have discoloured earlier when compared with the control sample. Discoloration observed during PVC degradation is due to the formation of conjugated polyene sequences ( $>4$ double bonds). Another phenomenon known in PVC degradation is chain scission and crosslinking. This step is likely to occur in presence of oxygen (auto oxidation) or during the ultimate steps of thermal degradation, leading to a dramatic change in PVC. Degradation rate is also strongly influenced by structural defect concentration, $\mathrm{HCl}$ formation or any strong Lewis acid or base, oxygen inducing auto oxidation. It can be assumed in the presence of peroxide these processes are accelerated and the discolouration is aggravated in formulations with TMPTMA and peroxide. In earlier work by Garcia- Quesada and Gilbert[13] it was reported that there is a slight improvement in thermal stability with increasing TMPTMA concentration, but an increase in degradation with addition of peroxide -compare NF3 with NF2, and NF5 with NF4. However, the samples with TMPTMA and peroxide show better dimensional stability at $190^{\circ} \mathrm{C}$ when compared 
with the control sample. This can be attributed to the increase in gel content of these samples which increases the resistance to the deformation of the samples.

\subsection{Glass transition temperature and heat of fusion:}

Table 3 shows the change in $\mathrm{T}_{\mathrm{g}}$ with changing concentrations of TMPTMA and peroxide. The crosslinked samples show a decrease in $\mathrm{T}_{\mathrm{g}}$ compared with the control sample even though they show a significant increase in gel content and higher tensile strength. Several investigations were carried out to explain this effect as earlier work $(13,16)$ has observed an increase in $T_{g}$. This effect could be attributed to the lubrication system used in the formulations for this investigation and due to the fact the new stabiliser used in this investigation is a liquid, not a powder material as the TBLS used previously. Table 3 also shows the change in degree of fusion with different concentrations of TMPTMA and peroxide. As expected it can be seen that there is an increase in extent of fusion with increasing processing temperature. It can also be seen that there is an increase in degree of fusion with the addition of TMPTMA and peroxide. This increase in fusion could be attributed to the excess TMPTMA present in the system. According to Gilbert et al.[15] plasticisers enhance the extent of fusion and Bowmer et al.[6] have shown that TMPTMA can act as a plasticiser on its own.

\subsection{Tensile properties:}

Results obtained for tensile properties at room temperature and at $130^{\circ} \mathrm{C}$ are shown in Figures 5, 6, 7 and 8 respectively. In the absence of both TMPTMA and peroxide the stress of break was 39.9 and $0.74 \mathrm{MPa}$ at room temperature and at $130^{\circ} \mathrm{C}$ respectively for pressing temperature $190^{\circ} \mathrm{C}$. As expected the tensile strength has increased with 
the addition of TMPTMA and peroxide. In fact as reported in work done earlier[13, 16] tensile strength has increased with higher TMPTMA concentration. As can be seen in figures 5 and 7 the higher tensile strengths were obtained with samples containing 15phr of TMPTMA; 58.4 and $1.47 \mathrm{MPa}$ at room temperature and at $130^{\circ} \mathrm{C}$ respectively. However, TMPTMA alone would not increase the tensile properties as reported in work done earlier by several researchers[10,15] as TMPTMA acts as a plasticiser. When TMPTMA and peroxide are present crosslinks are produced in PVC and the network formed here restricts the deformation. Hence, the material yields higher stress at break and lower elongation at break. However, increase in peroxide does not improve the tensile strength. Depending on the concentration of TMPTMA there is an optimum amount of peroxide needed to achieve better tensile properties. A tensile strength of $0.94 \mathrm{MPa}$ (when measured at $130^{\circ} \mathrm{C}$ ) is obtained for sample NF2 which contains 10phr of TMPTMA and 0.3phr of peroxide. However the tensile strength has decreased to $0.72 \mathrm{MPa}$ for sample NF3 which contains 10phr of TMPTMA but $0.6 \mathrm{phr}$ of peroxide, which shows that increasing the concentration of peroxide does not improve the tensile properties but that there is an optimum amount of peroxide required for different amounts of TMPTMA. The results obtained for tensile strength (when measured at $130^{\circ} \mathrm{C}$ ) for samples pressed at $190^{\circ} \mathrm{C}$ are consistent with the gel content obtained for samples pressed at $190^{\circ} \mathrm{C}$. Therefore the increase in tensile strength of these samples could be attributed to the chemical crosslinks formed by TMPTMA and the PVC. However, the tensile strength (when measured at $130^{\circ} \mathrm{C}$ ) of samples pressed at $200^{\circ} \mathrm{C}$ is higher than that of samples pressed at $190^{\circ} \mathrm{C}$, even though the gel content is lower. The increase in tensile strength in these samples can be contributed to two different factors; gel content and the extent of fusion. The relationship between tensile strength and fusion in these 
samples is shown in figure 9. It can be seen that in general there is an increase in tensile strength with increasing degree of fusion. As shown in table 3 the higher extents of fusion obtained here are for the samples pressed at $200^{\circ} \mathrm{C}$. (The high value for sample NF3 pressed at $190^{\circ} \mathrm{C}$ is a valid result, but unexplained at this stage). Thus, the increase in tensile strength obtained in samples pressed at $200^{\circ} \mathrm{C}$ (Fig 7) depends not only on the increase in gel content but also the contribution from the better fusion in PVC. It is known that tensile strength at room temperature increases with fusion level. This is true for high temperature tensile properties as well.

\subsection{FTIR Spectroscopy:}

Infrared spectroscopy is used here to detect the presence of unreacted TMPTMA by monitoring the residual unsaturation. When infrared spectroscopy was used for analysis two prominent absorbance peaks at $1721 \mathrm{~cm}^{-1}$ and at $1640 \mathrm{~cm}^{-1}$ were observed in the samples with TMPTMA and peroxide (figures 11 and 12). In earlier work by Garcia-Quesada and Gilbert[13], the peak at $1640 \mathrm{~cm}^{-1}$ was also observed and attributed to the residual unsaturation in TMPTMA. For comparison of samples this peak was compared to the $\mathrm{C}=\mathrm{O}$ peak from the TMPTMA at $1721 \mathrm{~cm}^{-1}$ which would not be expected to change in intensity. With addition of peroxide Trigonox 29C75, the peak ratio $A_{1640} / A_{1721}$ decreases showing that TMPTMA has reacted with the PVC chain. As can be seen from table 4 this ratio increases with increasing concentration of TMPTMA. With addition of the peroxide the ratio decreases confirming that there is a reaction between TMPTMA and PVC in the presence of peroxide. However, it can be seen in table 4 that even with increasing peroxide, residual unsaturation of sample NF4 has increased. Due to the bulky nature of the TMPTMA molecule $\left[\mathrm{CH}_{3} \mathrm{CH}_{2} \mathrm{C}\left(\mathrm{CH}_{2}-\mathrm{O}-\mathrm{CO}-\mathrm{CCH}_{3}=\mathrm{CH}_{2}\right)_{3}\right]$ it is likely that 
these molecules become sterically hindered due to restriction in mobility in the three dimensional TMPTMA - PVC network. Therefore, more unreacted double bonds remain in the system.

\section{Conclusions}

This investigation concludes that PVC can be successfully crosslinked with 10 and 15phr of trimethylolpropane trimethacrylate (TMPTMA) in the presence of peroxide Trigonox 29 - C75. Premature crosslinking during processing is largely avoided and a maximum gel content of 55\% has been obtained with 15phr of TMPTMA and 0.3phr of peroxide. Peroxide crosslinking can be carried out successfully in conjunction with the tin stabiliser used in this work. However, although elevated temperature properties of crosslinked PVC show some improvement, this is not reflected in $\mathrm{T}_{\mathrm{g}}$ values. The increase in tensile strength depends not only on the increase in gel content but also the better fusion in PVC.

Acknowledgement : One of the authors (AG) wishes to acknowledge the Royal Society of Chemistry for the provision of Daphne Jackson Fellowship.

\section{References}

1. Miller,A.A. Ind.Eng.Chem.1959,51,1271

2. Chapiro, A. J.Chim.Phys.1956,53,895

3. Alexander,P., Charlesby,A and Ross,M. Proc.Roy.Soc.Lond. 1954,223A,392

4. Pinner,S.H., Plastics, 1960, 25,35

5. Salmon,W.A. and Loan,L.D. J. Appl.Polym.Sci., 1972,16,671 
6. Bowmer, T.N., Davies, D.D., Kwei,T.K. and Vroom, W.I., J. Appl.Polym.Sci.,1981,26,3669

7. Bowmer, T.N., Hellman,M.Y., and Vroom, W.I.,J.Appl.Polym.Sci.,1983,28,2083

8. Bowmer, T.N., Hellman,M.Y., and Vroom, W.I.,J.Appl.Polym.Sci.,1983,28,2553

9. Nethsinghe, L.P. and Gilbert,M., Polymer, 1988,29,1935

10. Nethsinghe, L.P. and Gilbert,M., Polymer, 1989,30 , 35

11. Saethre, B. and Gilbert, M., Polymer, 1996, 37, 3379

12. Gilbert,M. and Garcia-Quesada, J.C., Plas.Rubb.Comp.,1999, 28, 125

13. Garcia-Quesada, J.C and Gilbert,M., J. Appl.Poly.Sc., 2000, 77, 2657

14. Hoang, Thai, Internal Report, IPTME, 2002

15. Gilbert,M, Hemsley, D.A. and Miadonye,A, Plastics and Rubber processing and Appl. I3(4) 1983,343

16.Thomas, N.L. and Zheng, X. , J. Appl. Poly. Sc.,DOI 10, 1002 
Table 1: New Formulation

\begin{tabular}{|l|c|}
\hline Material & Amount, phr \\
\hline PVC & 100 \\
\hline Tinstab BTS71N* & 4 \\
\hline Loxiol G10 V** & 1.2 \\
\hline Loxiol G52 or eSlip 2053 & 0.4 \\
\hline Interwax GP 25 & 0.2 \\
\hline Paraloid K120N & 1.5 \\
\hline TMPTMA & $0,10,15$ \\
\hline Trigonox 29- C75 & $0,0.3,0.45,0.6$ \\
\hline
\end{tabular}

*Composition:

\section{CAS No}

26864-37-9

10584-98-2

** Glycerol mono oleate

\section{Name}

n-Butyltin tris(2-

ethylhexylthio-glycolate)

Di-n-butyltin bis(2-

ethylhexylthio-glycolate)
Value \%

ca. 20

ca. 60 
Table 2: Key to the formulations

\begin{tabular}{|l|l|l|l|l|l|}
\hline & NF1 & NF2 & NF3 & NF4 & NF5 \\
\hline TMPTMA & 0 & 10 & 10 & 15 & 15 \\
\hline Peroxide & 0 & 0.3 & 0.6 & 0.3 & 0.45 \\
\hline
\end{tabular}


Table 3: Results calibrated from DSC traces

\begin{tabular}{|l|c|l|l|l|l|c|}
\hline \multicolumn{2}{|l|}{ TMPTMA } & 0 & 10 & 10 & 15 & 15 \\
\hline \multicolumn{2}{|l|}{ Peroxide } & 0 & 0.3 & 0.6 & 0.3 & 0.45 \\
\hline $\mathrm{T}_{\mathrm{g}}{ }^{\circ} \mathrm{C}$ & Samples Pressed at $190^{\circ} \mathrm{C}$ & 69 & 64 & 67 & 65 & 65 \\
\cline { 2 - 7 } & Samples Pressed at $200^{\circ} \mathrm{C}$ & 72 & 57 & 65 & 62 & 66 \\
\hline $\begin{array}{l}\text { Corrected } \\
\text { heat of fusion } \\
\text { (for } 100 \% \text { of } \\
\text { PVC) } \mathrm{Jg}^{-1}\end{array}$ & Samples Pressed at $190^{\circ} \mathrm{C}$ & 4.5 & 5.4 & 7.1 & 5.9 & 5.2 \\
\cline { 2 - 8 } & Samples Pressed at $200^{\circ} \mathrm{C}$ & 6.4 & 6.7 & 6.6 & 7.6 & 6.9 \\
\hline
\end{tabular}


Table 4: Measurements of residual unsaturation in samples with TMPTMA and peroxide

\begin{tabular}{|c|c|c|c|c|c|}
\hline \multicolumn{2}{|c|}{ Sample No } & \multicolumn{2}{|c|}{$\begin{array}{l}\text { Area of Absorbance at } \\
\text { Peak Numbers }\end{array}$} & \multirow[t]{2}{*}{$\begin{array}{l}\text { Ratio } \\
\mathbf{A}_{1640} / \mathbf{A}_{1721}\end{array}$} & \multirow[t]{2}{*}{$\begin{array}{l}\text { \% Unreacted } \\
\text { Crosslinks }\end{array}$} \\
\hline & & $1721 \mathrm{~cm}^{-1}$ & $1640 \mathrm{~cm}^{-1}$ & & \\
\hline \multicolumn{2}{|c|}{ TMPTMA(standard) } & 6.10 & 1.02 & 0.17 & \\
\hline \multirow{5}{*}{$\begin{array}{l}\text { Samples } \\
\text { pressed } \\
\text { at } 190^{\circ} \mathrm{C}\end{array}$} & & & & & \\
\hline & NF2 & 65.63 & 2.25 & 0.034 & 20.5 \\
\hline & NF3 & 58.74 & 1.85 & 0.032 & 18.9 \\
\hline & NF4 & 51.69 & 2.62 & 0.051 & 30.4 \\
\hline & NF5 & 49.68 & 1.95 & 0.039 & 23.6 \\
\hline \multirow{5}{*}{$\begin{array}{l}\text { Samples } \\
\text { pressed } \\
\text { at } 200^{\circ} \mathrm{C}\end{array}$} & & & & & \\
\hline & NF2 & 50.92 & 1.95 & 0.038 & 23.0 \\
\hline & NF3 & 52.11 & 2.22 & 0.043 & 25.5 \\
\hline & NF4 & 50.20 & 4.09 & 0.082 & 48.9 \\
\hline & NF5 & 48.37 & 3.17 & 0.066 & 39.3 \\
\hline
\end{tabular}

